\title{
DESIGN AND PARAMETRIC ANALYSIS ON AN INDUCED AIR COOLING EXHAUST SHELL
}

\author{
Wenwei Zeng ${ }^{1}$ Huaibao Zhang ${ }^{2, *}$ \\ ${ }^{1}$ University of Kentucky, Lexington, KY, 40506 \\ ${ }^{2}$ Sun Yat-sen University, Guangzhou, China, 510006
}

\begin{abstract}
A compact 500-watt $(\mathrm{W})$ portable multi-fuel rotary engine generator uses an enclosed cell to have the rotary engine unit, its auxiliary parts, and electrical wire harness packaged within it. The rotary engine exhaust gases temperature goes up to $700 \mathrm{C}$ when they are emitted from exhaust port, then hot exhaust gases sweep muffler. An induced air-cooling tube is designed and coated over muffler surface to keep its temperature under a safe level. Therefore, those subsystems in the genset, which could be subjected to significant amount of heat from the muffler surface, can be protected from structure failure. Parametric analysis of the inlet and outlet structures of the induced air-cooling muffler shell are mainly focused on and performed with the aid of the ANSYS workbench. In details, Response Surface Method (RSM) and Goal Driven Optimization (GDO) strategy in ANSYS suite was used to handle an array of sensitive design variables for a more efficient induced air cooling system. It is demonstrated that the inlet and outlet structures play an important role in the cooling airflow rate. Optimization of their structures leads into an induced airflow rate increased from 0.224 CFM (cubic foot per minute) to $11.20 \mathrm{CFM}$. The heat transfer performances of the optimized air-cooling muffler shell are evaluated, focusing on the heat convection and radiation from exhaust gases to the induced cooling air. It is shown that high cooling efficiency is achieved by the optimized air-cooling tube at low, intermediate to high output power up to $500 \mathrm{~W}$. The optimized air-cooling tube is then tested in a genset to check its cooling performance. The test result shows muffler shell surface temperature is controlled in a safe range.
\end{abstract}

KEY WORDS: Generator; Rotary Engine; Induced Air Cooling; Parametric Analysis; Exhaust System

\section{INTRODUCTION}

The study on the internal combustion engine exhaust system has become more and more important recently due to its key role in the design of advanced exhaust after-treatment systems to meet emission regulations. The transient simulation of heat transfer are rapidly employed in exhaust systems design and optimization phases [1] [2]. Konstantinidis et. al [1] proposed a novel solution procedure on a comprehensive transient computer model which converts all exhaust piping configurations, resulting in significant savings in processing time. Kandylas and Stamatelos [3] reviewed the relations and parameters which are involved in the computational modeling of of heat transfer in exhaust piping. The design of the exhaust manifold and piping significantly affects the exhaust gas inlet temperature into the particulate trap systems (i.e., diesel particular filter, (DPF) or gasoline particular filter (GPF)), and consequently, the temperature levels attainable inside the ceramic filter. Waermeatlas [4] found hot spot and corrosion on exhaust pipe and silencer was caused by high exhaust system temperature. Back pressure in exhaust pipe can be controlled by reducing exhaust temperature, which then improves the silencer efficiency.

*Corresponding Huaibao Zhang: zhanghb28@mail.sysu.edu.cn 
A significant number of researches work have been done on exhaust manifold, exhaust piping and catalytic converter packaging design for both on-road and off-road vehicles exhaust system to improve exhaust system (or aftertreatment) performance based on heat transfer analysis [5]. Durat et al. [6] carried out an experimental study and CFD simulation of gas flow in exhaust pipe to determine the optimum catalyst location for a spark ignition engine exhaust system. Dattatray et al. [7] dedicated to reducing hot spots in exhaust silencer through design improvement by thermal analysis, and they designed silencer with less hot spots and improved the life of exhaust system and its components.

Saider et al. [8] reviewed the latest developments and technologies on waste heat recovery of exhaust gas from internal combustion engine. Sorin et al. [9] studied instantaneous character of heat transfer coefficients in exhaust pipes for continuous and intermittent flows due to strict standards of emission regulation. They concluded transient solution of heat transfer equations were required to determine instantaneous character of heat transfer coefficients. Bannister et al. [10] developed an exhaust system model based on characterization of heat transfer to represent a range of configurations seen in an production versions. It's accurately simulating of heat transfer and subsequent catalyst light-off in similar production exhaust systems.

The high exhaust gas temperature will not only affect lifespan and performance of exhaust system components but other parts around them. When other components are setting to high temperature exhaust system, such as exhaust manifold, overheating can occur. In addition, cooled air from the radiator can quickly pick up heat once again as it passes over heat generating components nearby [2]. High temperature gases in exhaust system leads to thermal and fatigue failures, which then causes cracks in silencer. So it is necessary to perform heat transfer analysis for hot section of exhaust system to get better performance. Thermal mass and external insulation on exhaust system are main factors which affect the inlet gas temperature of catalytic converters. Under normal operating conditions, catalytic converters are most effective to reduce air pollution from internal combustion engines. Catalytic converters efficiency is sensitive to exhaust gas temperature. Therefore, high exhaust gas temperature flows through exhaust system need to be cooled before they reach catalytic converters, in order to keep catalytic converter performance [5].

During the development of a $500 \mathrm{~W}$ multi-fuel (gasoline, kerosene, alcohol, JP5, JP8 and E85 etc.) rotary engine generator, a "backpack size" generator, huge amount of heat is generated in a compact generator box. In order to control the inside temperature of the generator, a series of CFD and FEA simulations were performed. The exhaust system requirements of a rotary engine are remarkably different from those of a fourstroke reciprocating engine due to extreme high temperature of combustion gases of the former. The engine can run as high as 11000 revolution per minute (RPM) with JP-8, and the exhaust gas temperature can reach $1000 \mathrm{C}$ at exhaust manifold port with full throttle open. The exhaust gas temperature is above $700 \mathrm{C}$ with 8500 RPM in current study. Even worse, the exhaust system is enclosed in a compact box, and surrounded by electrical motor and wiring harness. Electrical motor efficiency decreases when the motor get hot, and wiring harness lifespan is shortened when it exposure in high temperature environment for a long time. An induced air cooling shell is used to cover the exhaust muffler, and take advantage of high temperature and high velocity exhaust gases to induce surrounding air to cool muffler surface. The classical induced air cooling applications for automobile exhaust system can be traced to patents "Engine and Exhaust Pipe Cooling System" [11] and "Air-cooled Muffler" [12].

In the remainder of this work, a comprehensive analysis on the induced air cooled muffler design are conducted with ANSYS FLUNET, where the original version of air cooled muffler is shown in the Fig 1. Flow arrow in blue means induced air flow, and flow arrow in yellow means exhaust gases, as showed in Fig 1 . In details, RSM and GDO strategy in ANSYS suite was used to handle an array of sensitive design variables for a more efficient induced air cooling system. The correlation of cooling efficiency and design variables are analyzed. The optimized structure is obtained after numerous iterations of CFD simulations. Zeng et al. [13] applied the same strategy on a research for optimizing a similar multi-fuel rotary engine water jackets. 


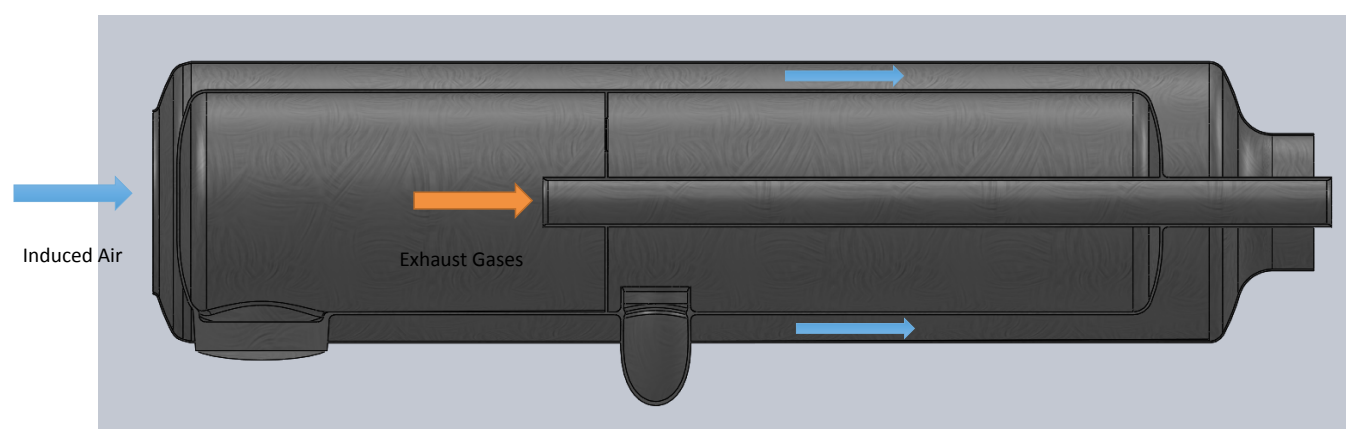

Fig. 1 Section Review of Air Cooled Muffler

\section{MODEL AND SIMULATION DESCRIPTION}

In this section, the heat transfer and fluid flow modeling for the induced air cooled muffler will be analyzed. Typically, there are two methods in CFD simulation to estimate exhaust system temperatures. High temperature and high pressure exhaust gases accelerates and expands when it exits from exhaust pipe to ambient environment, which generates external compressible flow. The accelerated exhaust flow can drag adjacent ambient air, and the latter is regarded as a "free cooling item", since it does not require any additional power to push through. A pressured based, Spalart-Allmaras turbulence model [14] is selected to perform transient heat transfer simulation due to its relatively low computational cost. Pressure-velocity coupling algorithm, 'Coupled Algorithms', is applied for discretization schemes. The coupled algorithm solves the momentum and pressure-based continuity equations together. Ideal gas law is utilized for solving compressible flow. Y plus at the wall is limited below 1, and grid independent was tested to ensure model accuracy. A typical grid independence test is applied to check grid function convergence to ensure model computational accuracy.

The Spallart-Allmaras turbulence model solves a modelled transport equation for kinematic eddy viscosity with the Boussinesq hypothesis. The transport equation for the Spalart-Allmaras model that can treat turbulent flow past a body with laminar regions is shown in Eq. 1 .

$$
\frac{\partial(\rho \tilde{v})}{\partial t}+u_{j} \frac{\partial(\rho \tilde{v})}{\partial x_{j}}=G_{v}+\frac{1}{\sigma_{\tilde{v}}}\left[\frac{\partial}{\partial x_{j}}\left((\mu+\rho \tilde{v}) \frac{\partial v}{\partial x_{j}}\right)+C_{b_{2}} \rho\left(\frac{\partial \tilde{v}}{\partial x_{j}}\right)^{2}\right]-Y_{v}+S_{\tilde{v}}
$$

Where $v$ is the transported variable, $\rho$ is the local density. $G_{v}$ and $Y_{v}$ are the turbulent viscosity production term and destruction term, individually. $\sigma_{\tilde{v}}$ and $C_{b 2}$ are the constants and $v$ is the molecular kinetic viscosity. $S_{\tilde{v}}$ is a user-defined source term. The turbulent dynamic viscosity, which can be used to model compressible flows, $\mu_{t}$, is from

$$
\mu_{t}=\rho \widetilde{v} f_{v 1}
$$

where the viscous damping function, $f_{v 1}$, is given by

$$
f_{v 1}=\frac{\chi^{3}}{\chi^{3}+C_{v 1}^{3}}, \chi \equiv \frac{\widetilde{v}}{v}
$$

At walls, the modified turbulent kinematic viscosity, $\widetilde{v}$, is set to zero. The fine mesh in used in this paper current paper is fine enough, and y plus near wall was below 1 . The wall shear stress is obtained from laminar stress-strain relationship as following

$$
\frac{u}{u_{\tau}}=\frac{\rho u_{\tau} y}{\mu}
$$

where $u$ is the velocity parallel to the wall, $u_{\tau}$ is the shear velocity, $y$ is the distance from the wall.

Although heat transfer analysis is important to exhaust system development, the main purpose of this paper is to investigate the correlation between induced airflow rate and muffler shell geometrical structure. The induced airflow is used to cool the muffler surface, therefore, the higher the induced airflow rate, the more heat the induced air can take away. The optimized goal is to get the maximum induced airflow. 


\subsection{Design Variables}

The exhaust flow exits from internal combustion engine exhaust port is highly transient. For simplicity, it is set as steady state (exhaust flow rate at rated power). Besides exhaust flow variation, there are numerous geometric variables can affect induced air flow, such as induced airflow inlet structure (AIS), mixer outlet structure, flow transitional length (TL), tube radius (TR), extended length (EL), muffler shell hydraulic diameter, and exhaust pipe diameter etc., as showed in the Fig. 2, will be analyzed. Muffler shell hydraulic diameter is set as $5 \mathrm{~mm}$ due to limited space in the generator box, and exhaust pipe is a constant in this application.

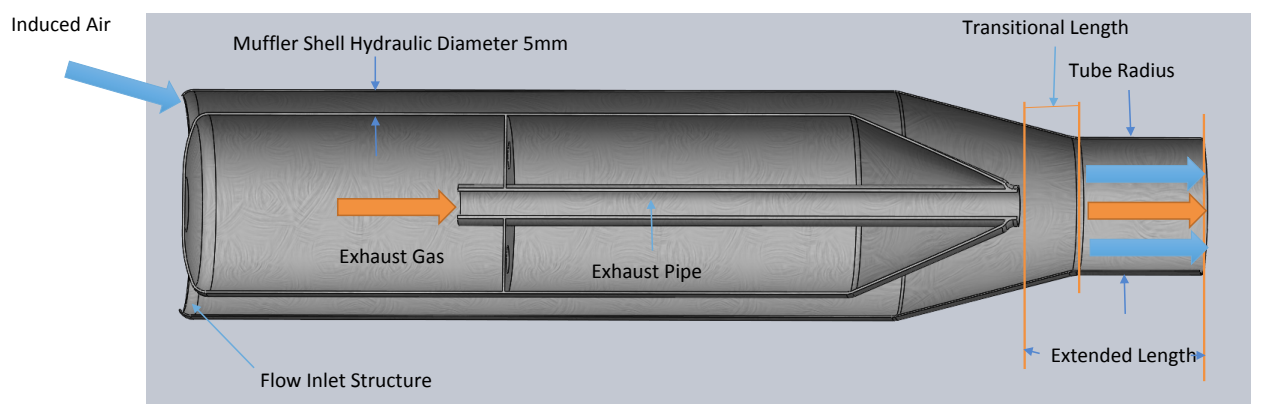

Fig. 2 Design Variables of Muffler Shell Structure

The induced air flow inlet structure can be classified into flared in, flared out and straight, as showed in Fig. 3(a) There are two flows inlets: exhaust gas inlet and induced air inlet. The boundary condition for exhaust gas is velocity inlet $(170 \mathrm{~m} / \mathrm{s}$ and $1.92 \mathrm{~atm}$ ) with constant temperature ( around $700 \mathrm{C}$ ); and for induced air is pressure inlet (ambient pressure). Exhaust gas exit from the exhaust pipe and mixes with induced air, then leaves from the same outlet, as showed in blue and yellow arrows in Fig. 2. Model geometry setting in ANSYS is showed in Fig. 3(b), where the left side is induced air inlet, the middle area is muffler shell, and left side is mixer gas outlet. Far away area with ambient pressure is set as boundary condition for both air inlet and mixer gas outlet, where large entrance and exit region are showed in Fig. 3(b).
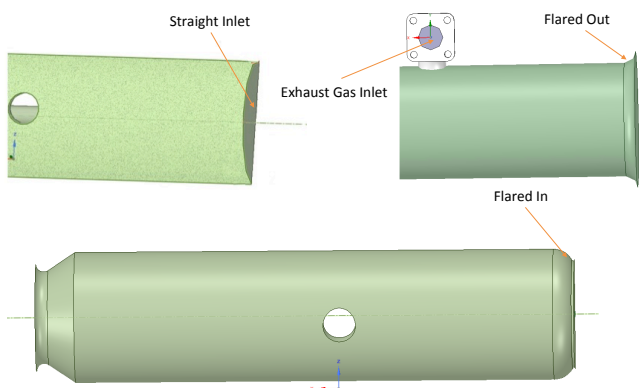

(a) Induced Air Flow Inlet Structure

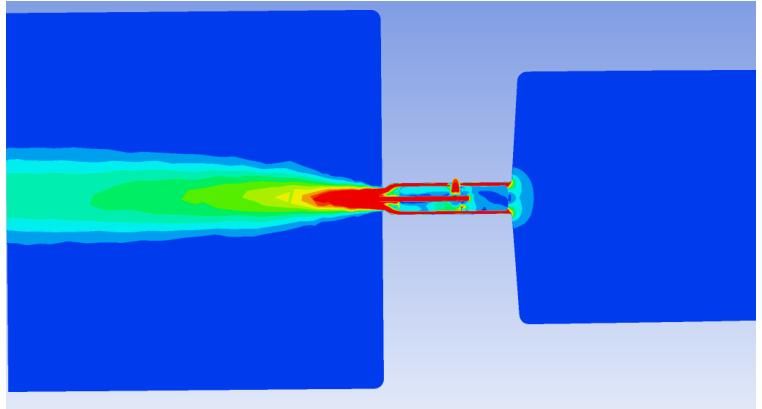

(b) Model Setting

Fig. 3 Model Geometry Settling

\section{SIMULATION RESULTS}

\subsection{Design of Experiments (DOE)}

The variables that showed in Fig. 2 includes AIS, muffler shell hydraulic diameter, exhaust pipe diameter, mixer flow outlet structure (includes TL, TR, and EL). Among them, muffler shell hydraulic diameter and exhaust pipe diameter are constant. The AIS and mixer flow outlet structures are design variables. The design variables are made of input metrics, and the exhaust shell surface temperature is the design target. The induced air is used to cool exhaust shell, thus, the induced airflow rate is regarded as the intermediate parameter in this study. The higher the induced air flow rate, the more cooling flow for reducing exhaust shell temperature.

3.1.1 Air Flow Inlet Structure Three types of air flow inlet structure are investigated, which are straight, flared in and flared out, as shown in Fig. 3(a). Induced airflow rate with different air inlet structures are listed 
in Table. 11. Where negative radius means flared in, zero radius means straight, and positive radius means flared out. The flared in and out structure affect air flow rate, with increasing of flare radius (from negative to positive), the induced air flow increased.

Table 1 Induced Air Flow Inlet Structure DOE

\begin{tabular}{lcccc}
\hline Cone Type & $\begin{array}{c}\text { Radius } \\
{[\mathrm{mm}]}\end{array}$ & $\begin{array}{c}\text { Air Flow Rate } \\
\text { CFM }\end{array}$ & $\begin{array}{c}\text { Mass Flow } \\
\mathrm{kg} / \mathrm{s}\end{array}$ & $\begin{array}{c}\text { Difference } \\
\%\end{array}$ \\
\hline Straight & 0 & 0.265 & $1.53 \mathrm{E}-4$ & 100 \\
& -8 & 0.224 & $1.29 \mathrm{E}-4$ & 85 \\
Flared In & -5 & 0.248 & $1.43 \mathrm{E}-4$ & 93 \\
& -3 & 0.258 & $1.49 \mathrm{E}-4$ & 97 \\
Flared Out & 5 & 0.271 & $1.56 \mathrm{E}-4$ & 102 \\
\hline
\end{tabular}

3.1.2 Mixer Flow Outlet Structure-Transition Length The investigation on mixer flow outlet structure includes three parts, and they are TL, TR and EL. Detailed DOE simulations are applied to these three parts to test sensitivity of induced air flow to the mixer flow outlet structure. The TL is defined as the length from exhaust gas pipe outlet to the end of transition area (minimum outlet tube radius), as showed in Fig. 2, The effect of TL to induced air flow is shown in Table 2, within TR sets as $15 \mathrm{~mm}$ and EL sets at $65 \mathrm{~mm}$.

Table 2 Mixer Flow Outlet-Transition Length

\begin{tabular}{cccccc}
\hline $\begin{array}{c}\text { Transition Length } \\
{[\mathrm{mm}]}\end{array}$ & $\begin{array}{c}\text { Extend Length } \\
{[\mathrm{mm}]}\end{array}$ & $\begin{array}{c}\text { Tube Radius } \\
{[\mathrm{mm}]}\end{array}$ & $\begin{array}{c}\text { Air Flow Rate } \\
\text { CFM }\end{array}$ & $\begin{array}{c}\text { Mass Flow } \\
\text { kg/s }\end{array}$ & $\begin{array}{c}\text { Difference } \\
\%\end{array}$ \\
\hline 0 & 65 & 15 & 7.97 & $4.59 \mathrm{E}-3$ & 94.96 \\
1.5 & 65 & 15 & 8.19 & $4.71 \mathrm{E}-3$ & 97.52 \\
3.5 & 65 & 15 & 8.11 & $4.67 \mathrm{E}-3$ & 96.63 \\
5.5 & 65 & 15 & 8.11 & $4.67 \mathrm{E}-3$ & 96.56 \\
6.5 & 65 & 15 & 8.20 & $4.72 \mathrm{E}-3$ & 97.74 \\
9.5 & 65 & 15 & 8.33 & $4.79 \mathrm{E}-3$ & 99.20 \\
10 & 65 & 15 & 8.39 & $4.83 \mathrm{E}-3$ & 100.00 \\
10.5 & 65 & 15 & 8.28 & $4.77 \mathrm{E}-3$ & 98.61 \\
11.5 & 65 & 15 & 8.22 & $4.74 \mathrm{E}-3$ & 97.97 \\
13.5 & 65 & 15 & 8.10 & $4.66 \mathrm{E}-3$ & 96.44 \\
15.5 & 65 & 15 & 8.18 & $4.71 \mathrm{E}-3$ & 97.44 \\
17.5 & 65 & 15 & 8.11 & $4.67 \mathrm{E}-3$ & 96.61 \\
19.5 & 65 & 15 & 8.17 & $4.70 \mathrm{E}-3$ & 97.33 \\
20.5 & 65 & 15 & 8.14 & $4.69 \mathrm{E}-3$ & 97.02 \\
25.5 & 65 & 15 & 7.96 & $4.58 \mathrm{E}-3$ & 94.79 \\
30.5 & 65 & 15 & 8.06 & $4.64 \mathrm{E}-3$ & 96.00 \\
35.5 & 65 & 15 & 7.93 & $4.57 \mathrm{E}-3$ & 94.44 \\
\hline
\end{tabular}

3.1.3 Mixer Flow Outlet Structure-Tube Radius The effect of mixer flow outlet TR to induced air flow rate is listed in the Table 3, within extended length sets at $65 \mathrm{~mm}$, and length of transitional sets at $10 \mathrm{~mm}$. The optimized tube radius for induced air flow is $15 \mathrm{~mm}$ as shown in Table 3 .

Table 3 Mixer Flow Outlet-Tube Radius

\begin{tabular}{cccccc}
\hline $\begin{array}{c}\text { Tube Radius } \\
{[\mathrm{mm}]}\end{array}$ & $\begin{array}{c}\text { Extend Length } \\
{[\mathrm{mm}]}\end{array}$ & $\begin{array}{c}\text { Transition Length } \\
{[\mathrm{mm}]}\end{array}$ & $\begin{array}{c}\text { Air Flow Rate } \\
\text { CFM }\end{array}$ & $\begin{array}{c}\text { Mass Flow } \\
\mathrm{kg} / \mathrm{s}\end{array}$ & $\begin{array}{c}\text { Difference } \\
\%\end{array}$ \\
\hline 10 & 65 & 10 & 6.32 & $3.64 \mathrm{E}-3$ & 75.28 \\
12.5 & 65 & 10 & 7.86 & $4.52 \mathrm{E}-3$ & 93.59 \\
13 & 65 & 10 & 7.92 & $4.56 \mathrm{E}-3$ & 94.30 \\
14 & 65 & 10 & 8.04 & $4.63 \mathrm{E}-3$ & 95.74 \\
15 & 65 & 10 & 8.40 & $4.83 \mathrm{E}-3$ & 100.00 \\
15.5 & 65 & 10 & 8.11 & $4.67 \mathrm{E}-3$ & 96.65 \\
16 & 65 & 10 & 8.04 & $4.63 \mathrm{E}-3$ & 95.77 \\
17.5 & 65 & 10 & 7.38 & $4.25 \mathrm{E}-3$ & 87.92 \\
20 & 65 & 10 & 6.12 & $3.53 \mathrm{E}-3$ & 72.94 \\
\hline
\end{tabular}


3.1.4 Mixer Flow Outlet Structure-Extend Length The parallel analysis showed mixer flow outlet TL at 10 $\mathrm{mm}$ and TR at $15 \mathrm{~mm}$ will be appropriate inputs to study EL. Detailed simulation results for EL are shown in Table. 4. Induced air flow rate is sensitive to the EL, and air flow rate increases with the increasing of extended length before it reached $165 \mathrm{~mm}$. While, the extended tube length is restricted by limited space of the genset box. As a result, the upper limit of EL is set as $65 \mathrm{~mm}$. Parameter correlation analysis for induced air flow and EL will be discussed in next section.

Table 4 Mixer Flow Outlet-Extend Length

\begin{tabular}{cccccc}
\hline $\begin{array}{c}\text { Extend Length } \\
{[\mathrm{mm}]}\end{array}$ & $\begin{array}{c}\text { Tube Radius } \\
{[\mathrm{mm}]}\end{array}$ & $\begin{array}{c}\text { Transition Length } \\
{[\mathrm{mm}]}\end{array}$ & $\begin{array}{c}\text { Air Flow Rate } \\
\text { CFM }\end{array}$ & $\begin{array}{c}\text { Mass Flow } \\
\mathrm{kg} / \mathrm{s}\end{array}$ & $\begin{array}{c}\text { Difference } \\
\%\end{array}$ \\
\hline 16 & 15 & 10 & 1.51 & $8.68 \mathrm{E}-4$ & 17.96 \\
25 & 15 & 10 & 2.29 & $1.32 \mathrm{E}-3$ & 27.32 \\
35 & 15 & 10 & 3.36 & $1.94 \mathrm{E}-3$ & 40.06 \\
45 & 15 & 10 & 4.98 & $2.87 \mathrm{E}-3$ & 59.31 \\
55 & 15 & 10 & 7.09 & $4.08 \mathrm{E}-3$ & 84.51 \\
65 & 15 & 10 & 8.39 & $4.83 \mathrm{E}-3$ & 100.00 \\
85 & 15 & 10 & 9.92 & $5.72 \mathrm{E}-3$ & 118.26 \\
105 & 15 & 10 & 10.62 & $6.12 \mathrm{E}-3$ & 126.60 \\
125 & 15 & 10 & 10.98 & $6.32 \mathrm{E}-3$ & 130.76 \\
145 & 15 & 10 & 11.20 & $6.45 \mathrm{E}-3$ & 133.51 \\
165 & 15 & 10 & 11.17 & $6.43 \mathrm{E}-3$ & 133.08 \\
215 & 15 & 10 & 11.03 & $6.35 \mathrm{E}-3$ & 131.34 \\
265 & 15 & 10 & 11.06 & $6.37 \mathrm{E}-3$ & 131.80 \\
315 & 15 & 10 & 10.89 & $6.27 \mathrm{E}-3$ & 129.81 \\
365 & 15 & 10 & 10.68 & $6.15 \mathrm{E}-3$ & 127.27 \\
\hline
\end{tabular}

\subsection{Parametric Analysis}

Changing the exhaust shell design variables can lead to change of the required pressure to elicit a volumetric flow, which then changes induced flow rate and air cooling efficiency. The RSM is used to estimate sensitivities of induced air flow rate to design variables. It showed induced airflow rate is not very sensitive to air flow inlet structure. Thus, air inlet structures will not be analyzed thoroughly in this section. Correlation matrix analysis is applied to evaluate correlation between design variables, which then used to find the optimized muffler shell design for maximum induced air flow rate. The optimized TL $(15 \mathrm{~mm})$ and TR $(10 \mathrm{~mm})$ are determined by correlation matrix analysis. Induced air flow rate is set as the design goal in GDO strategy. Due to the length of this paper, details of RSM, correlation matrix analysis and GDO strategy will not be exhibited. As a result, only correlation between design variables and induced airflow rate are shown. In details, 2D plots and polynomial interpolation equations for these correlations are presented .

3.2.1 Air Flow Inlet Structure A 2D plot of Flared Cone Radius vs. Induced Air Flow Rate is shown in Fig. 4. which is based on the original muffler shell structure, see Fig. 2. The blue line is original data as showed in Table 1, and dash dark line is linear fitted regression and the goodness-of-fit measure, $R^{2}$ is 0.828 . The induced air flow is not linear to flared cone radius, and the fitting line is just used to show the induced air flow rate trends to flared cone radius. The blue line showed the induced air flow rate increases with the increasing of flared cone radius, that is changing from flared in to flared out. Induced flow rate increased from 0.258 to $0.271 \mathrm{CFM}$ with flared cone radius increase from -3 to $5 \mathrm{~mm}$ (Table 1 ). The flared in structure will increase pressure drop across the exhaust shell, however, it's not significant. The reason is the induced flow is a passive flow, and the air flow velocity is very low at the inlet area, which will not cause high pressure drop. From material strength point, the flared-in structure is much stronger than that of flared-out, therefore, a flared-in $(-3 \mathrm{~mm})$ case is utilized as the final air flow inlet structure.

3.2.2 Mixer Flow Outlet Structure-Transition Length A 2D plot of Transition Length vs. Induced Air Flow Rate is shown in Fig. 5. The blue line is the original data, as showed in Table. 2, the dash dark line is linear fitted regression. In this plot, the other design variables, TR is fixed at $15 \mathrm{~mm}$, and EL is fixed at $65 \mathrm{~mm}$. The 


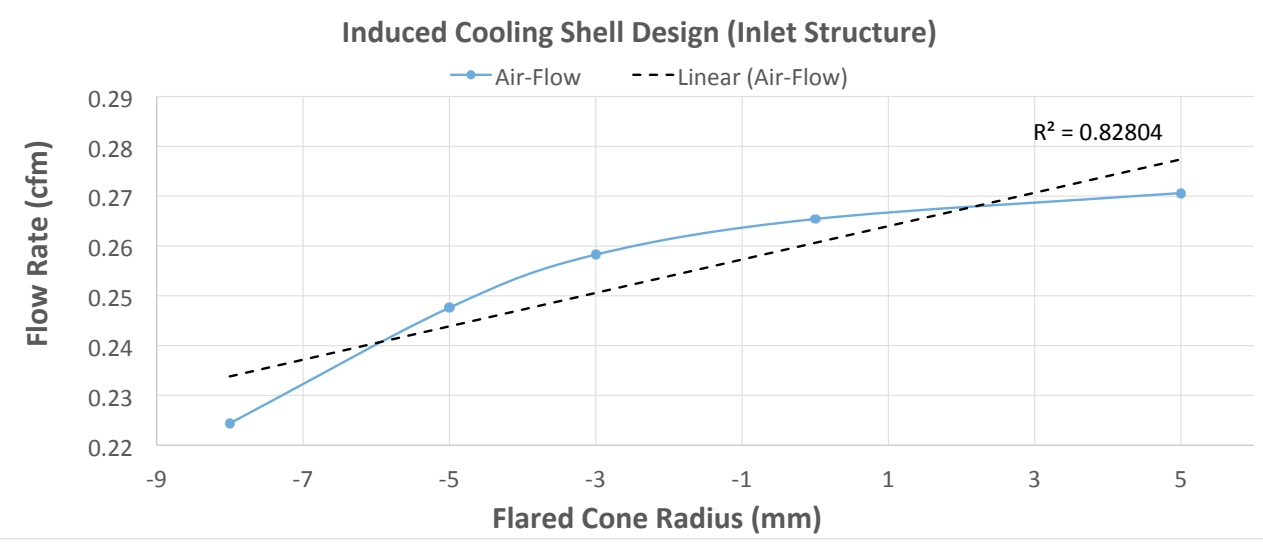

Fig. 4 Induced Air Flow Inlet Structure

design purpose of transition area and its shape is to align with outline of exhaust pipe cone, as showed in Fig. 2. The appropriate design should make air flow runs smoothly when it meets with exhaust gases at mixer tube. Induced air flow rate varies with the change of increasing TL, but it's hard to get a clearly correlation between them. Induced air flow rate reaches maximum when TL is $10 \mathrm{~mm}$, as showed in Fig. 5 .

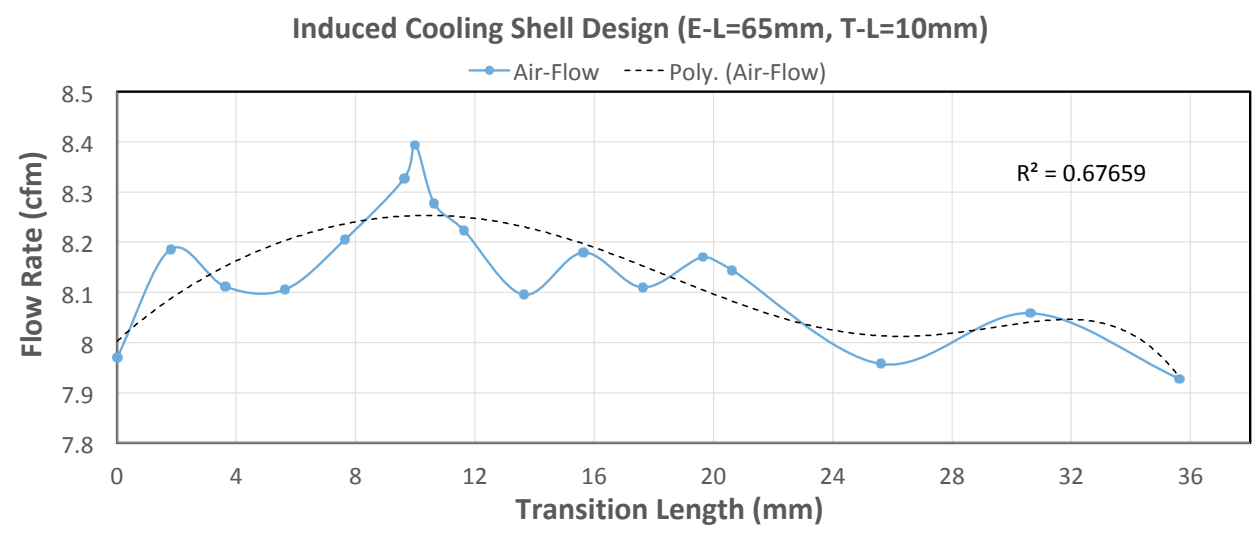

Fig. 5 Mixer Flow Outlet Transition Length

3.2.3 Mixer Flow Outlet Structure-Tube Radius A 2D plot of Mixer Flow Outlet Tube Radius vs. Air Flow rate is shown in Fig. 6. The blue line is the original data, as showed in Table. 3 , the dash dark line is linear fitted regression. In this plot, the other parameters, TL is fixed at $10 \mathrm{~mm}$, and EL is fixed at $65 \mathrm{~mm}$. The blue line shows the induced air flow rate increase with the increasing of TR at beginning, and it reaches maximum with TR at $15 \mathrm{~mm}$, then it turns down. Increasing TR can reduce flow restriction and pressure drop, but when TR increases to a certain level, (i.e $15 \mathrm{~mm}$ in this case), it will reduce exhaust gases dragging force on induced air that comes from air flow inlet as showed in Fig. 2.

3.2.4 Mixer Flow Outlet Structure-Extended Length A 2D plot of Mixer Flow Outlet Extend Length vs. Induced Air Flow Rate is shown in Fig. 7. The blue line is the original data as showed in Table. 4, the dash dark line is linear fitted regression. The fitting line is used to show the trends of induced air flow rate with changing of EL. In this plot, the other parameters, TR is fixed at $15 \mathrm{~mm}$, and TL is fixed at $10 \mathrm{~mm}$. The blue line shows induced air flow rate increases with the increasing of EL at beginning. It stops increasing after extended length beyonds $115 \mathrm{~mm}$, then it keeps flat around $11 \mathrm{CFM}$. The induced air flow rate is sensitive to the extended length. With EL increases from 16 to $165 \mathrm{~mm}$, the air flow rate increases from 1.51 to 11.17 CFM, as shown in Table 4. The air flow increases $739.7 \%$ by just changing EL. 


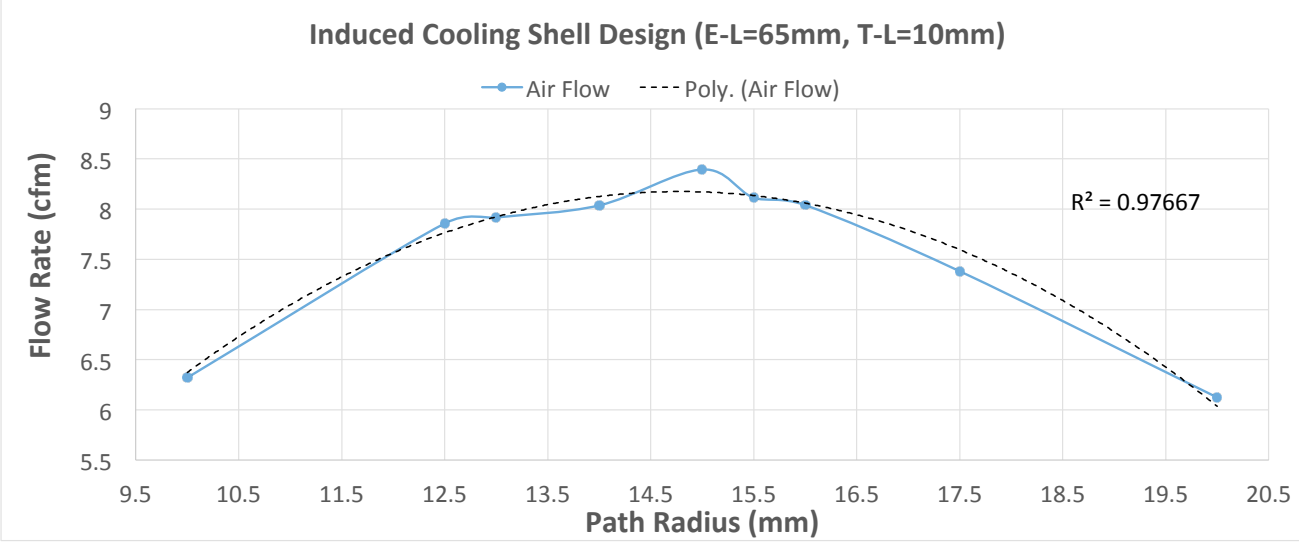

Fig. 6 Mixer Flow Outlet Tube Radius

The exhaust gases expands in the extended length tube, which can drag the surrounding air and cause volumetric pressure. Increasing of EL can increase the induced air flow rate, but it also increases frictional head loss. That's the reason induced air flow starts increasing, then keeps flat and final decreasing with increasing of EL. Due to the enclosed box space restriction, the EL is selected at $65 \mathrm{~mm}$ in final design, where corresponding induced air flow rate is $8.39 \mathrm{CFM}$.

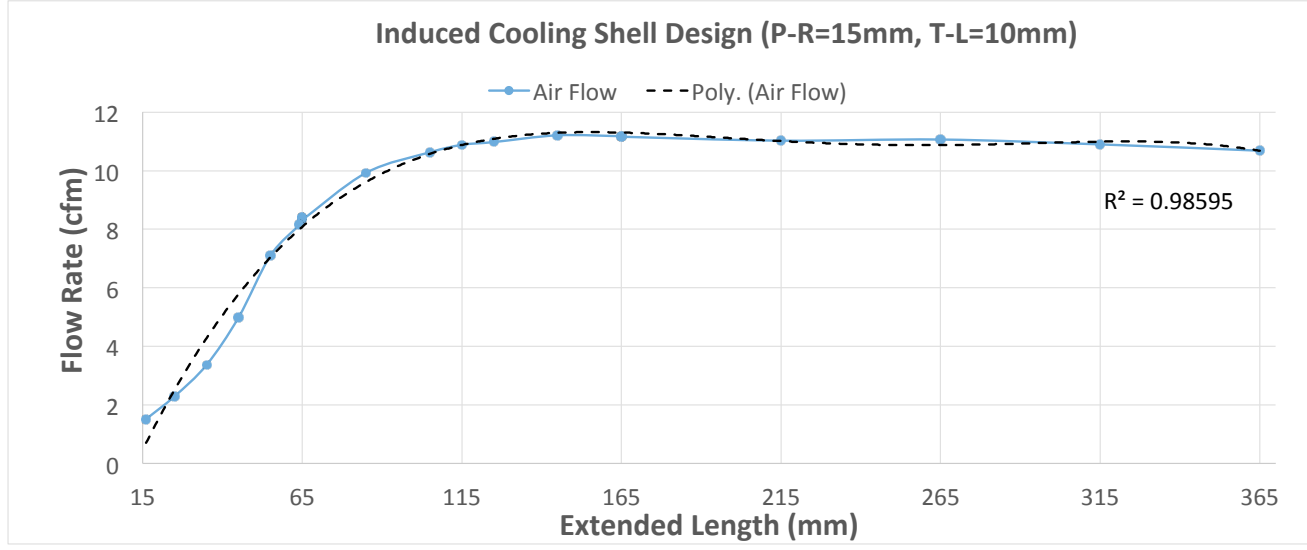

Fig. 7 Mixer Flow Outlet Extend Length

3.2.5 Optimized Structure The exhaust shell structure with $3 \mathrm{~mm}$ flared in air inlet structure, TL at $10 \mathrm{~mm}$, TR at $15 \mathrm{~mm}$, and EL at $65 \mathrm{~mm}$ were selected in the final exhaust shell design. The corresponding air flow rate for selected exhaust shell is, $8.40 \mathrm{CFM}$ or $4.83 \mathrm{E}-3 \mathrm{~kg} / \mathrm{s}$, which marked as $100 \%$ at the difference column in Table 23 and 4 . The conservation of energy equation can be used to calculate the amount of heat that induced air can take away from exhaust shell, the equation is listed as,

$$
Q_{h}=m C_{p} \Delta T
$$

where $Q_{h}$ is amount of heat transfer, $m$ is air mass flow rate, $C_{p}$ is idea gas specific heat capacities of air, $\Delta T$ is air temperature difference across exhaust shell. Assuming the induced air flow temperature at the exhaust shell inlet is $25 \mathrm{C}$, at outlet is $50 \mathrm{C}$, then the air temperature difference, $\Delta T$ is $25 \mathrm{C}$. With air temperature difference at $25 \mathrm{C}, C_{p}$ at $1.005 \mathrm{~kJ} / \mathrm{kg} . \mathrm{K}$, and induced air mass flow rate at $4.83 \mathrm{E}-3 \mathrm{~kg} / \mathrm{s}$, it's easy to get $Q_{h}$,

$$
Q_{h}=4.83 E-3 * 1.005 * 25=121 W
$$

A typical rotary engine with thermal efficiency about 30\%, radiator takes about $30 \%$ of heat, and the remaining $40 \%$ of rejected heat is carried away by the exhaust gases. In the current study, the rotary engine can generate $500 \mathrm{~W}$ power, and the amount of heat in exhaust gases is about $667 \mathrm{~W}$. The induced air from exhaust shell can 
take away $121 \mathrm{~W}$ from exhaust gases, which is about $18 \%$ of total heat in exhaust gases.

The velocity contours between original design and optimized structure are showed in Fig. 8, where exhaust gases flow and air flow comes from right side, and mixer flow leaves from left side of the images. Fig. 8(a) shows induced air flow velocity at the original muffler shell (right side of Fig. 8(a)) is smaller than $1 \mathrm{~m} / \mathrm{s}$, the corresponding air flow rate is 0.224 CFM. The air flow rate at the optimized muffler shell is higher than $10 \mathrm{~m} / \mathrm{s}$, as showed in right side of Fig. 8(b), The simulation results show the optimized structure can significantly increase induced air flow rate.

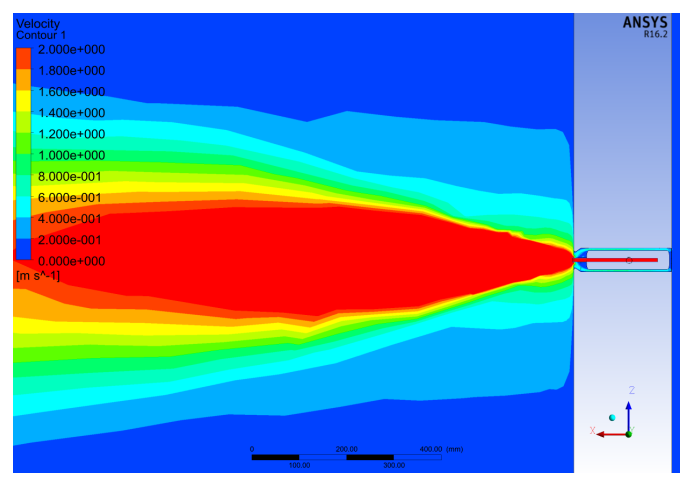

(a) Original Design

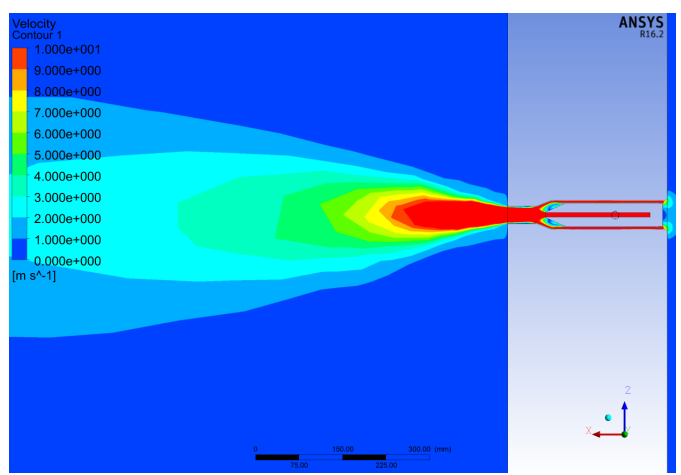

(b) Optimized Structure

Fig. 8 Muffler Shell Flow Velocity Contour

3.2.6 Experimental Validation The optimized muffler shell design is produced and tested in a controlled test cell to validate exhaust shell cooling efficiency. The initial test showed the optimized shell structure performed very well, and the exhaust surface temperature was decreased to a safe range. The genset with optimized exhaust shell is shown in Fig. 9, where exhaust shell surface temperature can be divided into three sections. The section A, with blue arrow, is air flow inlet area; section B, with red arrow, is exhaust flow inlet area; section $\mathrm{C}$, with yellow, is mixer gases outlet area.

The induced air flow temperature was $26 \mathrm{C}$ during this test. The exhaust shell surface temperature in section A was $36 \mathrm{C}$, section $\mathrm{B}$ was $68 \mathrm{C}$, and section $\mathrm{C}$ was $45 \mathrm{C}$ with engine runs at $8500 \mathrm{RPM}, 500 \mathrm{~W}$ over 10 minutes. Comparing to the original $700 \mathrm{C}$ exhaust gases, the current exhaust shell has a high efficiency to cool down exhaust pipe. Thus, the optimized exhaust shell can protect auxiliary parts or wiring harness in genest from overheat. More details about the experimental validation will be shown in future work.

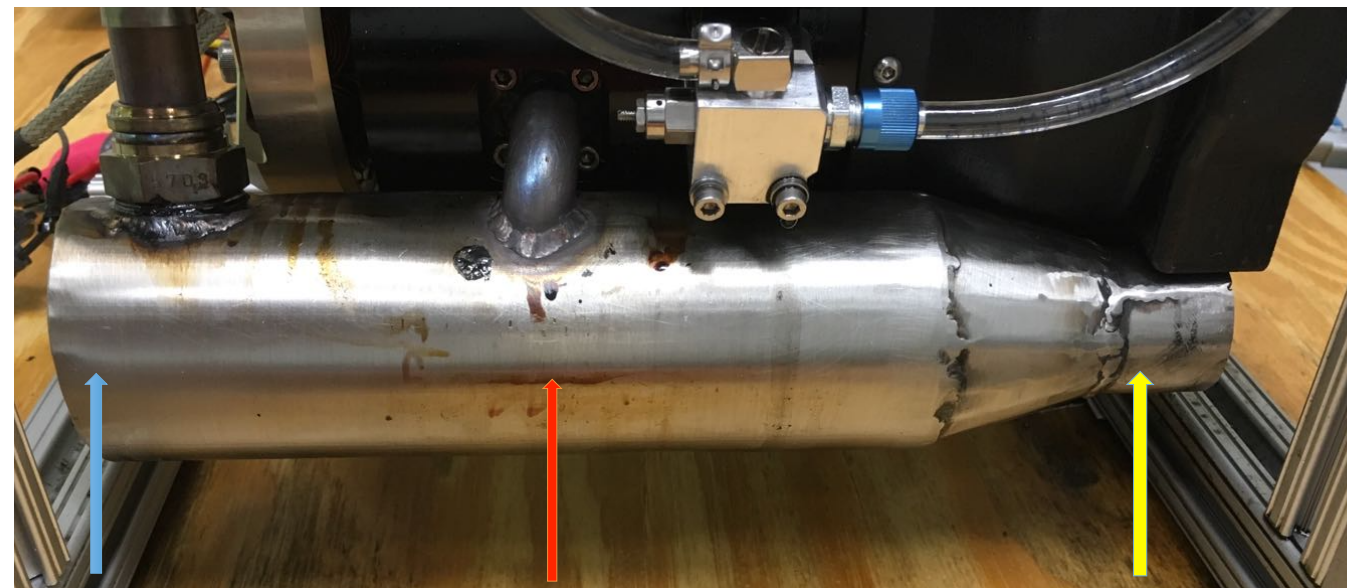

A

B

C

Fig. 9 Exhaust Shell Test Demo 


\section{CONCLUSIONS}

ANSYS CFD is utilized as a design tool to optimize exhaust shell structures for an enclosed compact size multi-fuel rotary engine generator. Design variables, such as air flow inlet structure, extended length, tube radius, transitional area length, are studied. Induced air flow rate is set as the design goal. Correlation of design variables to optimized goal are presented in tables, and figures. The induced air flow rate increased from 0.224 CFM to maximum 11.20 CFM, which increases by almost 50 times during optimization process. Extended length and tube radius are sensitive variables for the design goal. Due to limited space of generator box, extended length is selected as $65 \mathrm{~mm}$ rather than the maximum flow case $(145 \mathrm{~mm})$. The tube radius also affect the flow rate, but it does not as play a vital role as the extended tube length. The transitional length and air flow inlet structure are relatively non-sensitive variables for the design goal. Experimental validation is performed to show exhaust shell cooling efficiency.

This paper exhibits part of numerical simulation results from ANSYS, other results, such as temperature distribution, velocity contours, pressure distribution etc., are not presented. More studies, such as response surface method, correlation matrix of parameter analysis, goal driven optimization strategy and heat transfer analysis will be followed up.

\section{REFERENCES}

[1] P. A. Konstantinidis, G. C. Koltsakis, A. M. Stamatelos. Transient heat transfer modeling in automotive exhaust systems. In: Proc Inst Mech Engrs, Part C: J Mech Eng Sci 1997; pp: 211:1-15.

[2] G. Xiao, Transient simulation of heat transfers for vehicle exhaust system, Procedia Engineering, 126 ( 2015 ) pp: 410-415.

[3] I. P. Kandylas, A. M. Stamatelos, Engine exhaust system design based on heat transfer computation, Energy Conversion \& Management, 40 (1999), pp: 1057-1072

[4] Waermeatlas. Du sseldorf: VDI-Verlag, 1988.

[5] M. S. Vasava, P. V. Jotaniya, A review on heat transfer analysis on automotive exhaust system. International Journal of Innovative Research in Science, Engineering and Technology, 2015 (4) 2, pp: 558-561

[6] Durat, M., Parlak, Z., Kapsiz, M., Parlak, A., "CFD and experimental analysis on thermal performance of exhaust system of a spark ignition engine", Journal of Thermal Science and Technology, Vol. 33(2), pp.89-99, 2013.

[7] Dattatray, D. G., Shinde, V. B., Kulkarni, S. S., "Thermal analysis for motor bike exhaust silencer for ensuring reduction in hot spots through design enhancement", International Journal of Advanced Engineering Research and Studies, Vol. II/ IV, pp.134-137, 2013.

[8] Saidur, R., Rezaei, M., Muzammil, W. K., Hassan, M. H., Paria, S., Hasanuzzaman, M., "Technologies to recover exhaust heat from internal combustion engines", Renewable and Sustainable Energy Reviews, Vol. 16, pp. 56495659, 2012.

[9] Sorin, A., Bouloc, F., Bourouga, B., and Anthoine, P., "Experimental study of periodic heat transfer coefficient in the entrance zone of an exhaust pipe", nternational Journal of Thermal Sciences, Vol. 47(12), pp. 1665-1675, 2008.

[10] Bannister, C., Brace, C., Taylor, J., Brooks, T., \& Fraser, N. (2010). The use of multi-variate models for the prediction of heat transfer in vehicle exhaust systems. Proceedings of the Institution of Mechanical Engineers., 224(3), pp: 369-385.

[11] J. J. S. Fluor, "Engine and exhaust pipe cooling system”, US Patent. No. US2138001 A, (1938)

[12] P. E. Fluor, "Air-cooled Muffler", US Patent. No. US2363236 A, (1944)

[13] Zeng, W., Okun, S., "Numerical and Experimental Analysis on High Power Density Multi-Fuel Rotary Engine Heat Redistribution Optimization Design", Proceedings of the ASME 2017 Heat Transfer Summer Conference. Volume 2, Bellevue, Washington, USA. July 9-12, 2017. ASME. https://doi.org/10.1115/HT2017-4889

[14] P. R. Spalart, S. R. Allmaras, "A One-Equation Turbulence Model for Aerodynamic Flows”, AIAA Paper 92-0439, 1992 , 